\title{
Association between Parvovirus B19 and anemia in HIV-infected patients
}

\author{
Majid Nouri ${ }^{1}$, Parvin Kamakifar ${ }^{2}$, Niloofar Khodabandehlou ${ }^{3}$, Javid Sadri Nahand ${ }^{4}$, Ahmad Tavakoli ${ }^{4}$, \\ Fatemeh Norooznezhad ${ }^{5}$, Saba Sorayyayi ${ }^{6}$, Farhad Babaei ${ }^{7}$, Shayan Mostafaei*8,9, Mohsen Moghoofei*7,8
}

Received: 8 Jun 2019

Published: 16 Dec 2019

\section{Abstract}

Background: Human parvovirus B19 (B19V) can cause anemia in some patients, including those with compromised immunity system. There are a few studies on molecular epidemiology of B19V and its association with anemia in Iran. Therefore, the aim of this study was to determine the B19V DNA, IgM, IgG, genotyping, and viral load in HIV patients in different groups of pregnant women, general population, injection drug users (IDU), and Elite controllers. Also, the possible association of B19V with anemia was studied.

Methods: In this case-control study, B19V DNA, anti-B19V IgM, anti-B19V IgG, viral load, and hemoglobin level were assessed in 113 HIV positive patients and 72 healthy controls. Also, CD4+ T cell counts and HIV load were measured in the patients' group. All statistical analyses were done using STATA 14.2 software (Stata Corporation, College Station, Texas, USA). P value $<0.05$ was considered statistically significant.

Results: Among HIV patients, 19 (16.8\%) cases had B19V DNA, 3 (2.7\%) had B19V IgM, and 7 (6.2\%) had B19V IgG. In control group, the prevalence of B19V DNA, IgM, and IgG was $6(8.33 \%), 7(9.7 \%)$, and $19(26.4 \%)$, respectively. In subpopulations based on transmission routes, general population had the highest B19V IgG and DNA positivity prevalence and viral load level. There was no significant association between $\mathrm{B} 19 \mathrm{~V}$ antibodies and DNA with anemia.

Conclusion: The results demonstrated that B19V infection cannot be considered as a high-risk factor for anemia in adult HIV patients. However, further studies are needed to determine the exact role of B19V infection in HIV patients.

Keywords: Anemia, Parvovirus B19, Human immunodeficiency virus, Iran

Conflicts of Interest: None declared

Funding: None

*This work has been published under CC BY-NC-SA 1.0 license.

Copyright $($ Iran University of Medical Sciences

Cite this article as: Nouri M, Kamakifar P, Khodabandehlou N, Sadri Nahand J, Tavakoli A, Norooznezhad F, Sorayyayi S, Babaei F, Mostafaei Sh, Moghoofei M. Association between Parvovirus B19 and anemia in HIV-infected patients. Med J Islam Repub Iran. 2019 (16 Dec);33:137. https://doi.org/10.47176/mjiri.33.137

\section{Introduction}

Human parvovirus B19 (B19V) is a small non enveloped, ssDNA (single-stranded) virus which belongs to

Corresponding author: Dr Shayan Mostafaei, shayan.mostafaei@kums.ac.ir DrMohsen Moghoofei, mohsen.moghoofei@kums.ac.ir

1. Golestan Hospital Research Center, Tehran, Iran

2. Department of Microbiology, Faculty of Medicine, Zanjan University of Medical Sciences, Zanjan, Iran

3. Department of Internal Medicine, Faculty of Medicine, Iran University of Medical Sciences, Tehran, Iran

4. Department of Medical Virology, Faculty of Medicine, Iran University of Medical Sciences, Tehran, Iran

5. Infectious Diseases Research Center, Kermanshah University of Medical Sciences, Kermanshah, Iran

6. Department of Clinical Biochemistry, Faculty of Medicine, Ardabil University of Medical Sciences, Ardabil, Iran

7. Department of Microbiology, Faculty of Medicine, Kermanshah University of Medical Sciences, Kermanshah, Iran

8. Medical Biology Research Center, Institute of Health and Technology, Kermanshah University of Medical Sciences, Kermanshah, Iran

9. Epidemiology and Biostatistics Unit, Rheumatology Research Center, Tehran University of Medical Sciences, Tehran, Iran
Parvoviridae family $(1,2)$. The transition routs for this virus include the respiratory route, mother to fetus, blood

$\uparrow$ What is "already known" in this topic:

Parvovirus B19 infection is involved in several clinical manifestations such as erythema infectiosum, chronic arthritis, hydrops fetalis, and transient aplastic crisis in patients with sickle cell anemia and pure red cell aplasia in immunocompromised hosts. This virus can lead to self-limited anemia in healthy individuals; however, it can develop into chronic anemia in immunocompromised cases.

\section{$\rightarrow$ What this article adds:}

The present study evaluated the association between anemia and $\mathrm{B} 19 \mathrm{~V}$ in HIV patients. Also, the threat of B19V is limited in the HIV patients receiving ART, whereas persistent B19 viremia in the untreated patients may lead to anemia. 
transfusion, and blood products $(3,4)$. B19V infection can cause various clinical manifestations such as erythema infectiosum, chronic arthritis, hydrops fetalis, transient aplastic crisis in patients with sickle cell anemia, and pure red cell aplasia in immunocompromised hosts $(5,6)$. The main site of B19V replication is inside the erythroid progenitor cells, bone marrow (7). Although it leaves no clinical impact on healthy individuals, it could cause anemia in immunocompromised hosts $(3,8)$. In the course of $\mathrm{B} 19 \mathrm{~V}$ infection, a brief period of viremia occurs which is mostly self-limited. This low-level viremia may persist in healthy individuals for about 12 months. However, in immunocompromised patients, it could lead to viral persistence and chronic bone marrow suppression and finally anemia due to the absence of an adequate antibody response $(9,10)$. This anemia occurs because of the inadequate immune response in immunosuppressed individuals who fail to control the primary infection of the virus (11). B19V infection and the consequent anemia are considered serious issues in HIV patients. A proportion of patients are cured by blood transfusions and high-dose intravenous immunoglobulin (12-15).

This study aimed to investigate the presence of B19V specific markers and its genotype patterns in different groups of HIV positive patients, including pregnant women, elite controllers, injection drug users (IDUs), and general population with different counts of $\mathrm{CD}^{+} \mathrm{T}$ cells. Also, in this study, it was aimed to determine the possible association between B19V and anemia in these patients.

\section{Methods \\ Study population}

A total of $113 \mathrm{HIV}$-infected patients and 72 control (healthy) persons participated in this case-control study between January 2016 and December 2017 in Tehran and Kermanshah.

Inclusion criteria were defined as cases referred to Iranian Research Center for HIV/AIDS, accessibility to fresh samples, and patients being from Kermanshah and Tehran. Exclusion criteria included any medical history of radiotherapy and/or chemotherapy, or systemic inflammatory disease such as rheumatoid arthritis and biologic anticancer therapies. Patients were classified into 4 subgroups, including pregnant women, general population, IDU, and elite controller. Elite controllers were defined as a group of HIV-positive individuals who, without any antiretroviral therapy (ART), had plasma viral loads below the detection limit along with a CD4 cell count similar to the healthy controls. Patients were further classified into 3 subgroups according to their $\mathrm{CD}^{+} \mathrm{T}$ cells/ $\mathrm{mm}^{3}$ as $\mathrm{CD}^{+}$ $\mathrm{T}<200, \mathrm{CD}^{+} \mathrm{T}=200-500$, and $\mathrm{CD} 4^{+} \mathrm{T}>500$. This study has been approved by the local institutional ethical committee under the Ethics Code of 14121472, and all procedures were in accordance with the Helsinki Declarations. Those participants who met the case and control definitions were asked to fill a written informed consent.

\section{Serology}

All plasma samples were screened for anti-B19V-IgM and anti-B19V-IgG using an enzyme-linked immunosorbent assay (ELISA) Kit (Abcam, MA, USA), according to the manufacturer's standard protocol.

\section{Nucleic acid extraction}

DNA extraction from $200 \mathrm{~mL}$ of plasma was performed by QIAamp MinElute Virus Spin Kit (Qiagen, Hilden, Germany), according to the manufacturer's recommendation. The extracted DNA was stored at $-70^{\circ} \mathrm{C}$ until further analysis.

\section{B19V detection, genotyping, and viral load}

For amplification of target DNA, the following items were used: $1 \mu \mathrm{L}$ of DNA, $2 \mathrm{X}$ Master mix (sinacolon, Iran), $1 \mu \mathrm{M}$ of each primers (8) (Metabion, Germany), $0.8 \mathrm{mM}$ deoxynucleotide mix, $2.5 \mathrm{mM} \mathrm{MgCl} 2,0.02 \mathrm{U} \mu \mathrm{l}-1 \mathrm{Taq}$ polymerase (Invitrogen, CA, USA ), 5\% DMSO and DDS up to $25 \mu \mathrm{L}$. Amplification was performed in a thermocycler (EppendorfMastercycler ${ }^{\circledR}$, Massachusetts, USA) for 40 cycles with the following temperatures: $95^{\circ} \mathrm{C}$ for 1 minute (denaturation), $55^{\circ} \mathrm{C}$ for 45 seconds (annealing), ${ }^{\mathrm{r}}{ }^{\circ} \mathrm{C}$ for 1 minute (extension), and $72^{\circ} \mathrm{C}$ for 10 minutes (final extension). Agarose gel electrophoresis $(1.5 \%)$ of PCR products was performed using $1 \mathrm{mM}$ TrisBorate-EDTA (TBE) buffer and the 100-bp DNA ladder (Sinaclon, Iran) at $90 \mathrm{~V}$ for 50 minutes. Finally, the desired DNA bands were observed using green viewer dye (Sinaclon, Iran).

Genotyping was conducted based on the protocol described by Azadmanesh et al (12). QIAquick PCR purification Kit (Qiagen, Hilden, Germany) was used for purification of nested PCR products from samples. Then, the positive samples for the NS1/VP1 region of B19V genome were sent for sequencing performed by Bioneer (Korea). The B19V DNA positive samples were analyzed using real time-PCR technique to determine B19 viral load, whose assessment has already been described by Koppelman et al (16). Accordingly, the set of primers which target a certain region in NS1 (nucleotides 2082 2099 and 2254-2274 of the genome with GenBank accession number AF162273) was used. Both protocols used the same set of primers targeting the same region of NS1 and were described previously by Koppelman et al.

\section{CD4+ T cell count and HIV viral load}

The CD4 count was performed using a flow cytometer FACSCalibur (Becton Dickinson Biosciences, USA). To determine HIV viral load, Cobas TaqMan (COBAS TaqMan; Roche Molecular Systems, Branchburg, NJ) was applied.

\section{Anemia determination}

According to the WHO standards, a hemoglobin value of below $13 \mathrm{~g} \mathrm{dL}^{-1}$ for men, below $12 \mathrm{~g} \mathrm{dL}^{-1}$ for women, below $11 \mathrm{~g} \mathrm{dL}^{-1}$ for pregnant women, and below $12 \mathrm{~g} \mathrm{dL}^{-1}$ for children were considered as severe anemia (17). CELLDYN RUBY Hematology Analyzer (Abbott Diagnostics) was used to determine hemoglobin level.

\section{Statistical analysis}

Continuous data were represented as mean \pm standard 
deviation (SD) or median \pm interquartile range (IQR). The statistically significant differences between experimental groups were assessed by one-way ANOVA or KruskalWallis $\mathrm{H}$ test. Categorical data were displayed as $\mathrm{N}(\%)$ and Chi-square or Fisher's exact tests were used for comparision. Also, the odds ratio $(95 \% \mathrm{CI})$ as the effect size of the association between the markers of B19V and HIV was estimated using logistic regression model. All statistical analyses were done using STATA 14.2 software (Stata Corporation, College Station, Texas, USA). Statistical significance was set at $\mathrm{p}$ value less than 0.05 .

\section{Results}

In the present study, $113 \mathrm{HIV}$-positive patients and 72 adults with no immunologically compromised cases were enrolled. In HIV group, 72 (63.7\%) of patients were male, with the mean \pm SD age of $36.221 \pm 9.933$ years, and this proportion for healthy controls was $49(68.1 \%)$, with the mean \pm SD age of $38.44 \pm 10.351$ years.

The mean CD4 count was $402.69 \pm 341.451$ cells $/ \mathrm{mm}^{3}$ in the patients and $1172.32 \pm 279.116$ cells $/ \mathrm{mm}^{3}$ in the healthy controls $(p<0.001)$. The mean of the B19 viral load in HIV patients was significantly higher than that of the healthy group $(\mathrm{p}=0.002)$. B19V DNA was detected in $19(16.8 \%)$ patients. B19V IgG and IgM were detected in the blood of $7(6.2 \%)$ and $3(2.7 \%)$ patients, respectively. One patient was positive for both IgG and IgM antibodies. Also, one patient was positive for B19V DNA and IgM simultaneously. The results of statistical analysis did not show any significant differences between the case and control groups in B19V IgM, while the prevalence of B19V IgG in controls was significantly higher than in the cases $(26.4 \%$ vs $6.2 \%, \mathrm{p}<0.001$, OR: $95 \%$ CI $=0.184$ : 0.073-0.466). All B19V samples were confirmed as Genotype I, subtype B19-1A, using a phylogenetic analysis. More details are demonstrated in Table 1.

Considering the patients being classified according to their $\mathrm{CD}^{+}$cell count, there were no significant differences in the distribution of B19V, antibodies, and DNA in the 3 subgroups. However, patients with CD4 cell counts $>500 \mathrm{~mm}^{-3}$ had a significantly higher prevalence of IgG and IgM. On the other hand, patients with CD4 cell counts 200-500 $\mathrm{mm}^{-3}$ had a significantly higher prevalence of B19V DNA. Among these patients, the average B19 viral load was higher in the subgroup with the lower CD4 count $(\mathrm{p}=0.038)$. The mean of the B19 viral load was the highest, 882.2 \pm 129.06 , in patients with CD4 count $<200$. More details on the prevalence of B19V DNA, antibodies, and viral load in the CD4 count subgrouping of patients are presented in Table 2.

Patients were classified into 4 subgroups: $12.43 \%$ pregnant women, $23.8 \%$ general population, $18.4 \%$ IDUs, and $6.5 \%$ elite controllers. The mean of the B19 viral load was $334.9 \pm 105.2$ copies $/ \mathrm{mL}$ (lowest) in elite controllers and $764.8 \pm 129.41$ copies $/ \mathrm{mL}$ (highest) in pregnant women $(p=0.036)$. The elite controller samples had a significantly higher prevalence of $\operatorname{IgM}$ and $\operatorname{IgG}(\mathrm{p}=0.007$ and $\mathrm{p}=0.036$, respectively). More details are illustrated in Table 3.

The prevalence and level of B19V DNA were higher in anemia patients compared to the non anemia group (Table 4). Moreover, the prevalence of anti-B19 IgM antibodies

Table 1. Comparison of participants' characteristics between $113 \mathrm{HIV}+$ patients and 72 healthy controls.

\begin{tabular}{|c|c|c|c|c|c|}
\hline Characteristics & & HIV+ patients & Healthy Control & $\mathrm{p}$ & OR $(95 \% \mathrm{CI})$ \\
\hline Age (Year) ${ }^{*}$ & & $36.221 \pm 9.933$ & $38.44 \pm 10.351$ & 0.146 & NA \\
\hline CD4 count $^{*}$ & & $402.69 \pm 341.451$ & $1172.32 \pm 279.116$ & $<0.001$ & NA \\
\hline B19 Viral load * (copies/ml) & & $1302.4 \pm 186.33$ & $227.6 \pm 109.72$ & 0.002 & NA \\
\hline \multirow[t]{2}{*}{$\mathrm{Sex}^{+}$} & Male & $72(63.7 \%)$ & $49(68.1 \%)$ & 0.454 & $0.824(0.441-1.542)$ \\
\hline & Female & $41(36.3 \%)$ & $23(31.9 \%)$ & 0.057 & $0.912(0.427-1.842)$ \\
\hline \multirow[t]{2}{*}{ B19V DNA (Genotype I) } & Presence & $19(16.8 \%)$ & $6(8.3 \%)$ & 0.045 & $2.223(0.843-5.867)$ \\
\hline & Absence & $94(83.2 \%)$ & $66(91.7 \%)$ & 0.064 & NA \\
\hline \multirow[t]{2}{*}{ Anemia $^{+}$} & Presence & $16(14.2 \%)$ & $5(7 \%)$ & 0.139 & $0.837(0.77-6.32)$ \\
\hline & Absence & $97(85.8 \%)$ & $67(93 \%)$ & 0.072 & NA \\
\hline \multirow[t]{2}{*}{$\operatorname{IgM}^{+}$} & Positive & $3(2.7 \%)$ & $7(9.7 \%)$ & 0.052 & $0.253(0.063-1.01)$ \\
\hline & Negative & $110(97.3 \%)$ & $65(90.3 \%)$ & 0.058 & \\
\hline \multirow[t]{2}{*}{$\mathrm{IgG}^{+}$} & Positive & $7(6.2 \%)$ & $19(26.4 \%)$ & $<0.001$ & $0.184(0.073-0.466)$ \\
\hline & Negative & $106(93.8 \%)$ & $53(73.6 \%)$ & $<0.001$ & \\
\hline \multirow[t]{5}{*}{ Sub-papulation ${ }^{+}$} & Healthy & - & $72(100 \%)$ & NA & NA \\
\hline & Pregnant Women & $23(12.43 \%)$ & - & & \\
\hline & IV Drug User & $34(18.4 \%)$ & - & & \\
\hline & Elite controller & $12(6.5 \%)$ & - & & \\
\hline & General population & $44(23.8 \%)$ & - & & \\
\hline \multirow[t]{3}{*}{ HIV load } & $\mathrm{No} \mathrm{Data}^{+}$ & $6(5.3 \%)$ & - & NA & NA \\
\hline & Undetectable $^{+}$ & $57(50.4 \%)$ & - & & \\
\hline & Detectable $^{*}$ & $31.42 \times 10^{4} \pm 8.08 \times 10^{4}$ & - & & \\
\hline
\end{tabular}

NA; Not applicable; * indicated as Mean \pm Standard Deviation; + indicated as N (\%).

Bold P-values represent as statistically significant

Table 2. Markers of B19V infection in HIV+ patients based on the CD4 count

\begin{tabular}{|c|c|c|c|c|}
\hline B19V Characteristics & $<200$ & $200-500$ & $>500$ & $\mathrm{p}$ \\
\hline $\mathrm{DNA}^{+}$ & $8 / 49(16.32 \%)$ & $9 / 39(23.7 \%)$ & $2 / 25(8 \%)$ & 0.302 \\
\hline $\operatorname{IgM}^{+}$ & $0 / 49(0.0 \%)$ & $1 / 39(2.6 \%)$ & $2 / 25(8 \%)$ & 0.099 \\
\hline $\mathrm{IgG}^{+}$ & $3 / 49(6.1 \%)$ & $1 / 39(2.6 \%)$ & $3 / 25(12 \%)$ & 0.323 \\
\hline B19 Viral load ${ }^{*}$ (copies/ml) & $882.2 \pm 129.06$ & $469.3 \pm 187.11$ & $237.1 \pm 126.50$ & 0.038 \\
\hline
\end{tabular}

+ indicated as $\mathrm{n} / \mathrm{N}(\%) ;$ * indicated as Mean \pm Standard Deviation.

Bold P-values represent as statistically significant 


\begin{tabular}{|c|c|c|c|c|c|}
\hline B19V Characteristics & Pregnant Women & IDU & Elite Controller & General population & $\mathrm{p}$ \\
\hline $\mathrm{DNA}^{+}$ & $5 / 23(21.7 \%)$ & $5 / 34(14.7 \%)$ & $1 / 12(8.33 \%)$ & $8 / 44(18.18 \%)$ & 0.780 \\
\hline $\operatorname{IgM}^{+}$ & $1 / 23(4.4 \%)$ & $0 / 34(0.0 \%)$ & $2 / 12(16.7 \%)$ & $0 / 44(0.0 \%)$ & 0.007 \\
\hline $\mathrm{IgG}^{+}$ & $1 / 23(4.4 \%)$ & $1 / 34(2.9 \%)$ & $3 / 12(25 \%)$ & $2 / 44(4.5 \%)$ & 0.036 \\
\hline B19 Viral load * (copies/ml) & $764.8 \pm 129.41$ & $672.4 \pm 111.78$ & $334.9 \pm 105.2$ & $441.0 \pm 109.6$ & 0.036 \\
\hline \multicolumn{6}{|c|}{$\begin{array}{l}\text { + Indicated as } \mathrm{n} / \mathrm{N}(\%) ; * \text { indicated as Mean } \pm \text { Standard Deviation. } \\
\text { Bold P-values represent as statistically significant }\end{array}$} \\
\hline \multicolumn{6}{|c|}{ Table 4. Markers of B19V infection in HIV+ patients with Anemia. } \\
\hline B19V Characteristics & \multicolumn{2}{|c|}{ Anemia group } & \multicolumn{2}{|c|}{ Non-anemia group } & $\mathrm{p}$ \\
\hline $\mathrm{DNA}^{+}$ & \multicolumn{2}{|c|}{$17 / 101(16.83 \%)$} & \multicolumn{2}{|c|}{$2 / 12(16.66 \%)$} & 0.675 \\
\hline $\operatorname{IgM}^{+}$ & \multicolumn{2}{|c|}{$1 / 16(6.25 \%)$} & \multicolumn{2}{|c|}{$2 / 97(2.06 \%)$} & 0.370 \\
\hline $\mathrm{IgG}^{+}$ & \multicolumn{2}{|c|}{$0 / 16(0.0 \%)$} & \multicolumn{2}{|c|}{$7 / 97(7.2 \%)$} & 0.591 \\
\hline B19 Viral load ${ }^{*}($ copies $/ \mathrm{ml})$ & \multicolumn{2}{|c|}{$911.3 \pm 187.52$} & \multicolumn{2}{|c|}{$302.4 \pm 186.33$} & 0.002 \\
\hline
\end{tabular}

+ Indicated as $\mathrm{n} / \mathrm{N}(\%) ; *$ indicated as Mean + Standard Deviation. Bold P-values represent as statistically significant

was higher in anemia patients than that of non-anemia group; nonetheless, the difference was not statistically significant $(\mathrm{p}=0.370)$.

\section{Discussion}

In the present study, the molecular and serological characterization of B19V was investigated in 4 groups of HIV patients in Tehran and Kermanshah, Iran. To our knowledge, this was the first study reporting the prevalence and genotyping of B19V in HIV patients and assessing the association between B19 infection and anemia within the mentioned subgroups. No previous study has been done with such categories and on elite controllers.

In this study, the prevalence of $\mathrm{IgG}, \mathrm{IgM}$, and $\mathrm{B} 19 \mathrm{~V}$ DNA in HIV-infected patients was $6.2 \%, 2.7 \%$, and $16.8 \%$, respectively. Studies that have been conducted in Iran included (a) Azadmanesh et al who reported 11.1\%, $1 \%$, and $13.1 \%$ for the prevalence of the $\operatorname{IgG}, \operatorname{IgM}$, and B19V DNA, respectively and (b) Abdollahi et al who stated the prevalence of $\mathrm{B} 19 \mathrm{~V} \operatorname{IgM}$ and $\mathrm{IgG}$ as $81.1 \%$ and $0 \%$, respectively $(12,18)$. In another study, the prevalence of $\mathrm{IgM}, \mathrm{IgG}$, and B19V DNA was reported to be $5.1 \%$, $67.3 \%$, and $15.3 \%$, respectively (19). This inconsistency of the $\mathrm{B} 19 \mathrm{~V}$ prevalence might have been due to the following reasons: the degree of immunodeficiency, sample size, and laboratory techniques. Also, it was demonstrated that the prevalence of B19V DNA was higher in cases than in controls $(16.8 \%$ vs $8.33 \%, \mathrm{p}<0.045)$, while the prevalence of B19V IgG was significantly lower in cases than in controls $(6.2 \%$ vs $26.4 \%, \mathrm{p}<0.001)$.

Consistent with the findings of the present study, various studies have documented low frequency of anti-B19V IgG antibodies among HIV-infected patients. This may be due to the impairment of the immune system and its inability to produce neutralizing antibody against B19V, which finally leads to chronic infection $(20,21)$. In this study and Gyllensten's group research, the prevalence of IgM in patients with CD4 level $<200$ was $0 \%$, whereas in another investigation by Pedranti et al, this value has been reported up to $10.8 \%$ for these patients $(19,22)$. An important limitation of epidemiology studies such as this study is the sampling period. When sampling is done immediately after the outbreak, the frequency is higher than interepidemic periods (1). Also, here, it was demonstrated that 15 cases had B19 viral load, while IgG and IgM were negative; and 4 cases were positive for B19 $\operatorname{IgG}$ and had viremia simultaneously. This situation could be due to an early acute or persistent phase of B19V infection. When the $\mathrm{B} 19 \mathrm{~V}$ infection gets chronic, it could lead to anemia in these patients. This result is inconsistent with the investigations conducted by He et al and Azadmanesh et al (12, 21). In this study, all B19V-positive samples were confirmed as genotype I. The genotype of the B19V in other studies vary in comparison to studies by Azadmanesh (Iran, genotype I), Grabarczyk (Poland, genotype I, II), and Plentz (Germany, genotype I, II, III) $(12,23,24)$. This variability could be explained as B19V genotype differs according to the geographical area. In HIV patients, the B19 viral load was significantly higher compared to the control group ( $\mathrm{p}=0.002)$ (Table 1). Also, B19 viral load in patients with $\mathrm{CD} 4^{+}$cells less than 200 was higher compared to other categories, demonstrating that $\mathrm{B} 19 \mathrm{~V}$ can replicate at a high level because of the lack of a functional immune system in these immunologically compromised patients (Table 2). However, in another investigation, the B19 viral load has been stated equal in all HIV-positive patients (19). This study also evaluated B19V characteristics in subgrouping of HIV patients, including pregnant women, general population, IV drug users, and elite controllers. This subgrouping was done considering the fact that the differences in the immunological and physiological status of these groups could be of great help in analysis. For example, elite controllers were considered the individuals with viral replication of undetectable levels without any ART and also with a CD4 level similar to healthy individuals (25). Here, it was found that the lowest mean of the B19 viral load was $334.9 \pm 105.2$ copies $/ \mathrm{mL}$ observed in elite controller group $(\mathrm{p}=0.036)$ (Table 3$)$. Also, it was shown that the elite controller samples had a significantly higher prevalence of $\operatorname{IgM}$ and $\operatorname{IgG}(\mathrm{p}=0.007$ and $\mathrm{p}=0.036$, respectively), indicating an effective immune system functioning in these patients. On the other hand, in IDUs, the prevalence of IgG was at the lowest rate, which could be a sign of the compromised condition of the immune system.

As previously mentioned, anemia is one of the major complications following $\mathrm{B} 19 \mathrm{~V}$ infection. On the other hand, there are several significant abnormalities in HIV patients among which anemia is highly important. This abnormality can use as a predictive marker for disease progression and mortality. Different factors can affect hemoglobin level, including immunological and hemato- 
logical conditions, opportunistic infections, and antiretroviral drugs and antimicrobials agents. Zidovudine (AZT) is an antiretroviral drug which can lead to anemia (26). In this study, AZT was the most commonly antiretroviral drug used by patients. Therefore, this study focused on these aspects in search for cases of anemia. Another factor affecting anemia was the B19V infection. Due to the inability of immune system to produce neutralizing antibodies against B19V, this infection could turn into a persistent infection or recurrent viremia which would further associate with chronic anemia (27). Abkowitz et al detected $17 \% \mathrm{~B} 19 \mathrm{~V}$ DNA in $30 \mathrm{HIV}$ patients with hematocrits (HCT) of $\leq 24$ and $31 \%$ of the patients with hematocrits less than 20. Therefore, they proposed that this virus probably causes severe anemia in HIV patients (28). In another similar investigation, B19V DNA has been found in 3 of 98 HIV patients with anemia. However, they found no significant association between anemia and B19V antibodies and DNA (19). Similar to this study, Pedranti et al indicated that there was no association between B19V DNA, IgM, and IgG with anemia. In our subgroup, anemia was observed at its highest rate of 6 cases $(37.5 \%)$ and lowest of $0(0 \%)$ cases in pregnant women and elite controllers, respectively. This high rate of anemia in pregnant women could be due to $\mathrm{B} 19 \mathrm{~V}$ infection resulting in weakened immune system finally failing to yield an adequate response to this infection (29).

\section{Conclusion}

The molecular and serological characterizations of B19V was investigated in HIV patients and healthy populations in Iran. Also, the association between anemia and B19V in HIV patients was evaluated. The results shrewdly indicated that the threat of $\mathrm{B} 19 \mathrm{~V}$ is limited in HIV patients receiving ART, whereas persistent B19 viremia in the untreated patients could lead to anemia. More detailed studies should be conducted to elucidate the role of B19V in HIV patients.

\section{Acknowledgments}

The authors are sincerely grateful to all participants for their contributions. Special thanks go to the director and staff of the HIV Laboratory of National Center for their valuable support. This research was not funded by any organization, and none of the authors received any form of financial support or grant for preparing this manuscript.

\section{Conflict of Interests}

The authors declare that they have no competing interests.

\section{References}

1. Pedranti M, Barbero P, Wolff C, Ghietto L, Zapata M, Adamo M. Infection and immunity for human parvovirus B19 in patients with febrile exanthema. Epidemiol Infect. 2012;140(3):454-61.

2. Shabani Z, Esghaei M, Keyvani H, Shabani F, Sarmadi F, Mollaie H, et al. Relation between parvovirus B19 infection and fetal mortality and spontaneous abortion. Med J Islam Repub Iran. 2015;29:197.

3. Kiani SJ, Javanmard D, Ghaffari H, Tavakoli A, Mortazavi HS, Bokharaei-Salim F, et al. Molecular prevalence of parvovirus B19 among HIV1-infected patients in Iran. Medical journal of the Islamic
Republic of Iran. 2018;32:113.

4. Tavakoli A, Monavari SH, Mollaei H, Bokharaei-Salim F, Esghaei M, Keyvani H, et al. Frequency of human Parvovirus B19 among patients with respiratory infection in Iran. Med J Islam Repub Iran. 2018;32:38.

5. Luo Y, Lou S, Deng X, Liu Z, Li Y, Kleiboeker S, et al. Parvovirus B19 infection of human primary erythroid progenitor cells triggers ATR-Chk1 signaling, which promotes B19 virus replication. J Virol. 2011;85(16):8046-55.

6. Javanmard D, Ziaee M, Ghaffari H, Namaei MH, Tavakoli A, Mollaei $\mathrm{H}$, et al. Human parvovirus B19 and parvovirus 4 among Iranian patients with hemophilia. Blood Res. 2017;52(4):311-5.

7. Arabzadeh SAM, Alizadeh F, Tavakoli A, Mollaei H, BokharaeiSalim F, Karimi G, et al. Human parvovirus B19 in patients with beta thalassemia major from Tehran, Iran. Blood Res. 2017;52(1):50-4.

8. Etemadi A, Mostafaei S, Yari K, Ghasemi A, Minaei Chenar H, Moghoofei M. Detection and a possible link between parvovirus B19 and thyroid cancer. Tumor Biol. 2017;39(6):1010428317703634.

9. Koduri PR. Parvovirus B19-related anemia in HIV-infected patients. AIDS Patient Care STDS. 2000;14(1):7-11.

10. Kerr J, Kane D, Crowley B, Leonard N, O'briain S, Coyle P, et al. Parvovirus B19 infection in AIDS patients. Int J STD AIDS. 1997;8(3):184-6.

11. Rivera ER, Cabanillas F. Severe anemia of rapid onset in an inmunocompromised host. Bol Asoc Med P R. 2008;100(3):42-6.

12. Azadmanesh K, Mohraz M, Kazemimanesh M, Aghakhani A, Foroughi M, Banifazl M, et al. Frequency and genotype of human parvovirus B19 among Iranian patients infected with HIV. J Med Virol. 2015;87(7):1124-9.

13. Maracy MR, Mostafaei S, Moghoofei M, Mansourian M. Impact of HIV risk factors on survival in Iranian HIV-infected patients: A Bayesian approach to retrospective cohort. HIV AIDS Rev Int J HIVRelat Prob. 2017;16(2):100-6.

14. Moghoofei M, Bokharaei-Salim F, Esghaei M, Keyvani H, Honardoost M, Mostafaei S, et al. microRNAs 29, 150, 155, 223 level and their relation to viral and immunological markers in HIV-1 infected naive patients. Future Virol. 2018;13(09):637-45.

15. Tavakoli A, Karbalaie Niya MH, Keshavarz M, Ghaffari H, Asoodeh A, Monavari SH, et al. Current diagnostic methods for HIV. Future Virol. 2017;12(3):141-55.

16. Koppelman M, Rood I, Fryer J, Baylis S, Cuypers H. Parvovirus B19 genotypes 1 and 2 detection with real-time polymerase chain reaction assays. Vox Sang. 2007;93(3):208-15.

17. Beutler E, Waalen J. The definition of anemia: what is the lower limit of normal of the blood hemoglobin concentration?. Blood. 2006;107(5):1747-1750.

18. Abdollahi A, Shoar S, Sheikhbahaei S, Mahdaviani B, Rasoulinejad M. Status of immunity against PVB19 in HIV-infected patients according to $\mathrm{CD} 4+$ cell count, and antiretroviral therapy regimen groups. Niger Med J. 2014;55(1):20.

19. Pedranti MS, Rodriguez-Lombardi G, Bracciaforte R, Romano N, Lujan P, Ricchi B, et al. Parvovirus B19 in HIV+ adult patients with different CD4+ lymphocyte counts. J Med Virol. 2017;66(12):17151721 .

20. van Elsacker-Niele A, Kroon F, Van der Ende M, Salimans M, Spaan W, Kroes A. Prevalence of parvovirus B19 infection in patients infected with human immunodeficiency virus. Clin Infect Dis. 1996;23(6):1255-60.

21. He M, Zhu J, Yin H, Ke L, Gao L, Pan Z, et al. Human immunodeficiency virus/human parvovirus B19 co-infection in blood donors and AIDS patients in Sichuan, China. Blood Transfus. 2012;10(4):502.

22. Gyllensten K, Jorup-Rönström C, Halvarsson M, Sönnerborg A, Yun Z. Parvovirus B19 infection in HIV-1 infected patients with anemia. Infection. 1994;22(5):356-8.

23. Plentz A, Würdinger M, Kudlich M, Modrow S. Low-level DNAemia of parvovirus B19 (genotypes 1-3) in adult transplant recipients is not associated with anaemia. $J$ Clin Virol. 2013;58(2):443-8.

24. Grabarczyk P, Kalińska A, Kara M, Wieczorek R, Ejduk A, Sulkowska E, et al. Identification and characterization of acute infection with parvovirus B19 genotype 2 in immunocompromised patients in Poland. J Med Virol. 2011;83(1):142-9.

25. Olson AD, Meyer L, Prins M, Thiebaut R, Gurdasani D, Guiguet M, et al. An evaluation of HIV elite controller definitions within a large 
seroconverter cohort collaboration. PloS One. 2014;9(1):e86719.

26. Agarwal D, Chakravarty J, Chaube L, Rai M, Agrawal NR, Sundar S. High incidence of zidovudine induced anaemia in HIV infected patients in eastern India. Indian J Med Res. 2010;132:386-389.

27. Setúbal S, Jorge-Pereira MC, Sant'Anna ALMd, Oliveira SAd, Bazin AR, Nascimento JPd. Clinical presentation of parvovirus B19 infection in HIV-infected patients with and without AIDS. Rev Soc Bras Med Trop. 2003;36(2):299-302.

28. Abkowitz JL, Brown KE, Wood RW, Kovach NL, Green SW, Young NS. Clinical relevance of parvovirus B19 as a cause of anemia in patients with human immunodeficiency virus infection. J Infect Dis. 1997; 176(1):269-73

29. Giorgio E, De Oronzo MA, Iozza I, Di Natale A, Cianci S, Garofalo G, et al. Parvovirus B19 during pregnancy: a review. J Prenat Med. 2010;4(4):63. 